\title{
EDITORIAL
}

\section{APPLYING THE AGE-FRIENDLY HEALTH SYSTEM FRAMEWORK TO LONG TERM CARE SETTINGS}

\author{
L.S. EDELMAN ${ }^{1,7}$, J. DROST ${ }^{2,7}$, R.P. MOONE $^{3,7}$, K. OWENS ${ }^{1,4}$, G.L. TOWSLEY ${ }^{1,7}$, \\ G. TUCKER-ROGHI ${ }^{5,8}$, J.E. MORLEY ${ }^{6,7}$
}

\begin{abstract}
1. Utah Geriatric Education Consortium, College of Nursing, University of Utah, Salt Lake City, UT, USA; 2. Summa Health, Division of Geriatric Medicine, Akron, Ohio, USA; 3. Minnesota Northstar GWEP, University of Minnesota Twin Cities, USA; 4. Avalon Health Care Management, Inc., Salt Lake City, UT, USA; 5. Domincan University of California, San Rafael, CA, USA; 6. Division of Geriatric Medicine, Saint Louis University School of Medicine, St. Louis, Missouri, USA; Authors are members of the Geriatric Workforce Enhancement Program Coordinating Center (GWEPCC) Long-Term Services and Supports Interest Group of the Geriatric Workforce Enhancement Programs; Disclosure: This project is supported by the Health Resources and Services Administration (HRSA) of the U.S. Department of Health and Human Services (HHS) as part of the following grants: 7. Grant

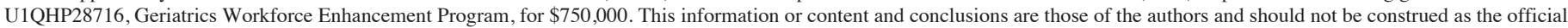
position or policy of, nor should any endorsements be inferred by HRSA, HHS, or the U.S. government; 8 . A Geriatric Academic Career Award award totaling $\$ 300,000$ with zero percentage financed with non-governmental sources. The contents are those of the author(s) and do not necessarily represent the official views of, nor an endorsement, by HRSA, HHS

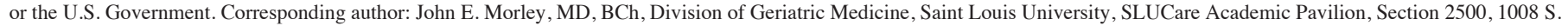
Spring Ave., 2nd Floor, St. Louis, MO 63110, USA, Email: john.morley@health.slu.edu, Twitter: @ drjohnmorley
\end{abstract}

Key words: Age-Friendly health system, long term care, elderly.

Recognizing the growing need for geriatric expert health care, a collaborative of the John A. Hartford Foundation, Institute for Healthcare Improvement (IHI), American Hospital Association, and Catholic Health Association of the United States established the Age-Friendly Health System (AFHS) initiative to increase quality, effective person-centered healthcare for older adults (1-3). Age friendly care follows evidence-based practices, causes no harm and focuses on "what matters" to each older adult, their family and caregivers. The four core elements - the 4Ms framework - provide an evidence-based framework for age-friendly care (Table 1). The 4Ms include "what matters", "mobility", "mentation", and "medications". The 4Ms are not meant to be implemented individually but rather incorporated together to provide agefriendly care (4).

\section{Table 1}

The 4Ms Framework of Age Friendly Health Systems

\begin{tabular}{ll}
\hline 4M Category & Description \\
\hline "what matters" & $\begin{array}{l}\text { Knowing and acting on what health outcomes and care } \\
\text { preference goals matter most now, and at the end of life. }\end{array}$ \\
"medications" & $\begin{array}{l}\text { Implementing medication reconciliation and } \\
\text { de-prescribing medications to be age-friendly. }\end{array}$ \\
"mobility" & $\begin{array}{l}\text { Creating an individual mobility plan and an environment } \\
\text { that enables mobility. }\end{array}$ \\
"mentation" & $\begin{array}{l}\text { Supporting cognitive functioning, maximizing } \\
\text { independence and dignity, identifying and treating } \\
\text { dementia, delirium and depression. }\end{array}$ \\
\hline
\end{tabular}

The AFHS movement initially focused on in-patient and acute care, with the goal of spreading the model to $20 \%$ of U.S. hospitals and health systems by 2020 . In 2019, the model was adapted for ambulatory care settings and the federal government's Health Resources and Services Administration (HRSA) Geriatric workforce Development Program (GWEP) included "transforming clinical training environments into integrated geriatrics and primary care systems to become agefriendly health systems" as a primary objective (5). Current GWEPs are encouraged to collaborate with their primary care partners, including nursing homes, to become age friendly.

It would appear that the nature of nursing home care would make it inherently age-friendly. For example, the Centers for Medicare \& Medicaid Services (CMS) regulatory and quality measures include data elements associated with the 4Ms. However, there is still much to be done to ensure that nursing home care is indeed person-centered and more than simply meeting quality measures at the facility level. True agefriendly care requires that interventions for each of the 4Ms are incorporated into each resident's care plan and that staff, the resident and their family are in agreement that the plan is in alignment with "what matters" most to the resident. Further, it is imperative that as the care plan is evaluated and updated and the resident's status changes to ensure that "what matters" most to the resident is honored through the end of life.

In the following sections, we discuss each of the $4 \mathrm{Ms}$ and how they can be addressed in nursing homes so that agefriendly care is woven into the culture of the nursing home and the care received by residents. An important component is to assure that meaningful activities that meet resident wishes are included in their daily activities (6). Meaningful activities are those that a resident wishes to engage in and enhance resident "mobility" and "mentation".

\section{"What Matters"}

IHI defines the domain "“what matters"” as "knowing and aligning care with an older adult's health outcome goals and care preferences." These health outcome goals and care Published online December 31, 2020, http://10.1007/s12603-020-1558-2 


\section{APPLYING THE AGE-FRIENDLY HEALTH SYSTEM FRAMEWORK TO LONG TERM CARE SETTINGS}

preferences are unique to each older adult and include current health goals and preferences and spans across care settings. Providing care that matters to older adults corresponds with person-centered care (7).

This is particularly important in long term care where conversations about end of life are paramount. Unfortunately, end of life conversations often only include the completion of advance directives, rather than a holistic understanding of what is important to nursing home residents, including current care preferences. Knowing "what matters" now may serve as a segue for end-of-life conversations (8). Eliciting "what matters" to older adults in any care scenario facilitates communication, establishes trust, and promotes well-being. In the ideal setting this information is obtained from the resident on admission and is updated at the quarterly resident care conferences.

Incorporating "what matters" into care delivery ensures care is person-centered, efficient, and effective and can be accomplished in multiple ways and at various levels. A nursing home could weave the $4 \mathrm{Ms}$ into mission and vision statements. A satisfaction survey asking residents and perhaps their families about "what matters" can be implemented after a new admission with routine follow up. Quality leaders can integrate "what matters" into their Quality Assurance and Performance Improvement (QAPI) monitoring.

An interprofessional care team can use resident care conferences to initiate and continue discussions that elicit "what matters" to each resident and develop strength-based care plans that address what is important to the resident. For example, it may matter to a resident that they have a weekly hair appointment. This can be documented and a schedule can be developed. Families play a key role in "what matters". For example, a family member learns that their aunt residing in a skilled nursing facility loves baseball and thus makes sure the recreational therapy team knows what teams and games she may enjoy watching. For example, if enough residents enjoy baseball, baseball reminiscence programs can be offered during the baseball season (9). Many nursing home residents are lonely and this has been exacerbated at the time of COVID-19. Implementing programs such as a "Circle of Friends" can greatly improve the outcome for these residents $(9,10)$. Implementing "what matters" into care delivery is the opportunity to provide care that aligns with preferences and supports person-centered care, which potentially results in better quality of life.

\section{Medications}

Older adults living in nursing homes are likely to be treated for three or more multiple chronic illnesses $(10,11)$. In addition, residents in nursing homes by definition have functional and/or cognitive decline, and often experience chronic or periodic symptoms that affect quality of life e.g., nausea, pain and constipation. To treat these chronic illnesses, physicians and advanced practice providers prescribe an average of 8.8 daily medications (12). Symptoms and impacts of prescriptions may pose additional challenges and result in more medications. Due to these factors, the AFHS focus on "medications" is critical to providing high quality care in a nursing home.

The AFHS paradigm acknowledges that medications are often necessary but that they must be used in a manner that does not interfere with the other $4 \mathrm{Ms}$ of care. Specifically, highrisk medications such as those that are highly anticholinergic, benzodiazepines, opioids, sedatives, and antipsychotics must be routinely screened for and assessed for risk. Many medications may not be appropriate for a person receiving palliative care at the end of life. Many older persons in nursing homes are on age-inappropriate medicines. All medicines should be checked against the Beers or STOPP criteria $(13,14)$. Also, they should be checked for drug-drug interaction and whether they are helping the condition they were started for (15).

Clinical and regulatory processes are in place for residents of nursing homes that address medications. Monthly pharmacy reviews identify medication interactions, potential gaps in medication indications, and high-risk medications. Prescribers receive academic detailing and suggestions for dose adjustments or alternative treatments as needed. Over the past several years, there has been increased attention to the risks associated with psychoactive medications in particular including benzodiazepines, antidepressants, and antipsychotics. Nursing staff at facilities have increased routine surveillance for potential side effects on psychoactive medications. Similarly, facilities have specific regulations in place that limit the use of antipsychotic medications.

Embedding medication management within the other 4Ms is critical to developing the best strategy to care for these vulnerable older adults. There are well-established risks to cognition and mobility associated with high-risk medications (16). Given the burden of multi-morbidity, "what matters" to the individual and their family regarding treatment goals must be addressed. Routine care-planning meetings with staff provides one opportunity to discuss medication management in light of the plan of care for the individual.

Medication management and optimization will continue to be a focus in nursing homes because of the high burden of chronic illness disease and symptom management needs of many residents. Ongoing education and systematic supports for the healthcare team will be needed to continue to improve agefriendly care.

\section{Mobility}

Falls pose a major risk to the health and well-being of older adults living in nursing homes and can result in serious injury, hospitalization, death, and a reduction in quality of life. Greater than $50 \%$ of nursing homes residents fall each year, and previous falls, mobility device use, and moderate disability are known risk factors that increase the likelihood of falls 


\section{THE JOURNAL OF NUTRITION, HEALTH \& AGING}

(Centers for Disease Control and Prevention (CDC) $(17,18)$. Age-friendly nursing homes incorporate the concept of mobility to ensure each resident moves safely every day to maintain function.

There is a transactional relationship between "mobility and the other $4 \mathrm{Ms}$. For example, residents living in nursing homes who take three or more daily central nervous system medications are more likely to have a serious fall than those not taking CNS medications (19). Additionally, there is growing evidence supporting aerobic exercise to slow cognitive decline related to mild cognitive impairment and dementia.

In an AFHS nursing home, "mobility" is explored by an interdisciplinary team (IDT), with a holistic perspective that addresses all of the 4Ms. Consider a resident with middle stage dementia who is refusing to participate in a restorative nursing program for ambulation and exercise and becomes fearful and aggressive during transfers. In response to the resident's neuropsychiatric behaviors, psychotropic medications are used as needed and the use of a transfer lift is being considered due to safety concerns. Members of the IDT meet for a clinical review of the resident's mobility and factors related to the other 4Ms. The team finds that when the resident is provided with extra processing time, simplified communication strategies, and multisensory cues, the resident is able to follow simple one-step directions and transfer safely without the use of the lift. The team works with the resident to identify enhancements to existing exercise programs that the resident finds enjoyable, e.g., dancing or bingo. Such person-centered care fits within the 4Ms framework for "what matters" by adapting exercise programs addressing "mobility" to fit with resident preferences (20), taking into account that preferences are often influenced by both ethnic and gender differences (21).

Fall prevention programs and fall committees in nursing homes work to prevent falls and restorative nurse aides often carry out functional maintenance plans designed to maintain functional mobility. It is important to recognize that up to a third of falls in nursing homes may be syncopal or presyncopal. The F3ALLS approach allows falls management to be patient centered (22). Using the AFHS framework, the interdisciplinary team in the nursing homes will address all of the 4Ms using a holistic approach as they consider opportunities to enhance mobility and prevent falls for residents.

\section{Mentation}

IHI defines Mentation as the prevention, identification and treatment of dementia, depression and delirium across settings of care. Mentation is of particular import as the prevalence of these conditions is substantial in nursing homes. In 2016, forty-eight percent of individuals living in a nursing home had a diagnosis of dementia (23). Dementia is the greatest risk factor for the development of delirium during hospitalization, and a recent study indicated that $16 \%$ of patients discharged to SNFs have unresolved delirium $(24,25)$. Additionally, over the past decade, the proportion of newly admitted nursing home residents admitted with mental illness other than dementia, has overtaken the proportion of those admitted with dementia only (26).

The interdisciplinary team in nursing homes conduct a variety of comprehensive assessments of cognition, that are useful, not only for identifying dementia related symptoms, but more importantly, for identifying preserved cognitive abilities that can be supported through modification of the environment, task adaptations and the use of communication and cueing strategies that facilitate engagement and participation. Through comprehensive interprofessional assessments the IDT identifies ways to adapt meaningful activities and routines based on the resident's level of cognition. Understanding an individual's specific cognitive challenges and remaining abilities is essential to supporting person-centered care and "what matters" to each individual. With an age-friendly approach to "mentation", the IDT communicates findings on assessments and acts on findings in a coordinated way through the care plan process.

An important component of mentation is to identify potentially treatable causes of cognitive impairment such as depression, hearing impairment, and vitamin B12 deficiency (27). Nursing homes should include as many elements of the Mediterranean or MIND diets as are acceptable to residents. Exercise, computer games, socialization, metformin in persons with diabetes, and management of cardiovascular risk factors also appear to slow progression of cognitive impairment. Cognitive stimulation therapy has been successful in improving cognition in those with mild to moderate dementia $(28,29)$. It also decreases depression and improves quality of life.

An important element of age-friendly care is that it occurs across settings. At times nursing homes serve as a transitional setting between acute settings and home- and communitybased settings. In addition to addressing the "mentation" needs of older adults while they are residents of the nursing home, the IDT also plays an important role in preparing the older adult to have successful care transitions within the continuum of care. Older adults who receive care in nursing homes are often well known to the healthcare professionals and staff who have valuable information that can be shared with other healthcare providers who may not know the older adult as well. For example, older adults experiencing dementia or delirium may not be able to express their needs or tell a new healthcare provider "what matters" to them in their daily care.

Developing systems of communication within the local healthcare system and continuum of care to share vital information about the 4Ms may help to prevent delirium when residents of nursing homes are hospitalized. As many as 50\% of older adults who are hospitalized experience delirium, and as many as $30 \%-40 \%$ of cases of delirium are preventable through interventions addressed in the $4 \mathrm{Ms}$ such as early mobilization, support for sensory impairments and orientation to surroundings (30-32).

Residents of nursing homes are also commonly transferred 


\section{APPLYING THE AGE-FRIENDLY HEALTH SYSTEM FRAMEWORK TO LONG TERM CARE SETTINGS}

back to the community receiving support from home health providers, family caregivers and community-based organizations. Communicating with other care providers about mentation and all of the 4Ms is essential to prepare older adults for successful discharges and prevent readmission to the facility or an acute care facility.

\section{Capturing the $4 \mathrm{Ms}$}

As described above capturing the essence of the $4 \mathrm{Ms}$ in nursing homes is completed through a number of interdisciplinary assessments conducted by many different departments and staff. At the core of the care management process is the Minimum Data Set (MDS). The MDS assessment focuses on gathering comprehensive and personalized data for each resident and patient (33). Categories of data collection in relation to the 4Ms Framework are shown in Table 2.

\section{Table 2}

Correlation between the MDS and the 4Ms

\begin{tabular}{ll}
\hline 4M Category & MDS Item \\
\hline All & $\begin{array}{l}\text { Items which inform each of the 4M categories: Diagnoses, } \\
\text { Hearing Speech \& Vision, Bladder \& Bowel, Health } \\
\text { Conditions, Swallowing/Nutritional Status, Oral/Dental } \\
\text { Status, Skin Conditions, Special Treatments }\end{array}$ \\
"what matters" & $\begin{array}{l}\text { Preferences for Customary Routine \& Activities, } \\
\text { Participation in Assessment and Goal Setting }\end{array}$ \\
"medication" & $\begin{array}{l}\text { Medication (This includes incorporating response } \\
\text { to monthly pharmacy reviews and pharmacy }\end{array}$ \\
& $\begin{array}{l}\text { recommendations on significant medication concerns) } \\
\text { "mentation" }\end{array}$ \\
"mobility" & $\begin{array}{l}\text { Functional Status, Functional Abilities and Goals, } \\
\text { Restraints }\end{array}$ \\
\hline
\end{tabular}

Once the comprehensive assessment process is completed, the IDT is guided to complete a more detailed review of specific areas which were triggered for additional assessment. The IDT works with the resident and, as appropriate, the resident's family to create personalized care plan interventions. This process is completed upon admission, quarterly and with significant changes in condition.

While the MDS Assessment does include diagnosis information, the predominance of assessments focuses on how the resident health status and disease states impact functional capabilities. This approach aligns well with the AFHS initiative and framework. Table 2 illustrates the specific alignment between the MDS and the 4Ms. The IDT can incorporate the $4 \mathrm{Ms}$ into the nursing home's existing care management structured. The integration of the MDS process with the 4Ms strengthens the team's ability to provide person-centered care to each resident.

\section{Conclusion}

An important asset of nursing homes is the interprofessional team that has often known the patient over a prolonged period of time. Staff often have a "long-view" of the older adult that is valuable to share with healthcare practitioners up and down the continuum of care who may be encountering the older adult for the first time with little to no background information or life history. Providing high quality age-friendly care to a nursing home resident requires a high quality interprofessional team. Nursing homes play a critical role in ensuring that agefriendly practices are communicated during transitions within the continuum of care.

At the time of COVID-19, the ability to provide good age-friendly care has been diminished due to lockdown and isolation further being disrupted by the pandemic (35). Many older persons with "long COVID" symptoms need rehabilitation which includes both attention to "mobility" and "mentation" (36). It is important that the nursing home team look for innovative ways to enhance age-friendly care at this time. To do this, it is essential to have availability of personal protective equipment and access to diagnostic testing which gives rapid results.

\section{Disclosures: The authors declare there are no conflicts.}

\section{References}

1. Mate KS, Bermaan A, Laderman M, Kabcenell A, Fulmer T. Creating age-friendly health systems - a vision for better care of older adults. Healthc (Amst) 2018;6(1):4 6.

2. Fulmer T, Mate KS, Berman A. The age-friendly health system imperative. J Am Geriatr Soc 2018;66:22-24.

3. Sanford AM, Berg-Weger M, Morley JE. Aging friendly health systems. J Nutr Health Aging 2019;23:119-121.

4. Institute for Healthcare Improvement. July 2020. http://www.ihi.org/Engage Initiatives/Age-Friendly-Health-Systems/Documents/IHIAgeFriendlyHealthSystems GuidetoUsing4MsCare.pdf

5. Health Resources Services Administration. Geriatrics Workforce Enhancement Program. 2019; https://www.hrsa.gov/grants/find-funding/hrsa-19-008.

6. Morley JE, Philpot CD, Gill D, Berg-Weger M. Meaningful activities in the nursing home. J Am Med Dir Assoc 2014;15:79-81.

7. Koren MJ. Person-centered care for nursing home residents: The culture-change movement. Health Aff (Millwood). 2010;29:312-317. Doi.10.1377/hlthaff.2009.0966. Epub 2010 Jan 7. PID: 20056692.

8. Towsley GL, Hirschman KB. Talking about end-of-life care: Perspectives of nursing home residents. Geriatric Nursing 2018;39:72-76.

9. Wingbermuehl C, Bryer D, Berg-Weger M, et al. Baseball reminiscence league: A model for supporting persons with dementia. J Am Med Dir Assoc 2014;15:85-89.

10. Berg-Weger M, Morley J. Editorial: Loneliness in older age: An unaddressed health problem. J Nutr Health Aging 2020;24:243-245

11. Berg-Weger M, Morley JE. Editorial: Loneliness and social isolation in older adults during COVID-19 pandemic: Implications for gerontological social work. J Nutr Health Aging 2020;24:456-458.

12. Moore KL, Boscardin WJ, Steinman MA, et al. Patterns of chronic co-morbid medical conditions in older residents of U.S. nursing homes: differences between the sexes and across the agespan. J Nutr Health Aging. 2014 Apr;18(4):429-36.

13. Aprahamian I, Morley JE. Editorial: To drug or not to drug: The geriatrician dilemma of polypharmacy. J Nutr Health Aging 2020;24:809-811.

14. Moore KL, Patel K, Boscardin WJ, et al. Medication burden attributable to chronic co-morbid conditions in the very old and vulnerable. PLoS One. $2018 \mathrm{Apr}$ 23;13(4): 0196109

15. Hale D, Marshall K. Update on the 2019 AGS Beers criteria. Home Healthcare Now 2020;38(4):222. July/August

16. Saraf AA, Petersen AW, Simmons SF, Schnelle JF, Bell SP, Kripalani S, Myers AP, Mixon AS, Long EA, Jacobsen JML, Vasilevskis EE, MAGS Prevalence in Olde 


\section{THE JOURNAL OF NUTRITION, HEALTH \& AGING}

Adults. J. Hosp. Med 2016;10;694-700. doi:10.1002/jhm.2614

17. Welsh TJ, McGrogan A, Mitchell A. Deprescribing in the last years of life - It's hard to STOPP. Age Ageing 2020;Aug 24;49(5):723-724.

18. Centers for Disease Control. Falls in Nursing Homes. 2014. Available at http://www. cdc.gov/HomeandRecreationalSafety/Falls/nursing.html. Accessed Nov 10, 2020.

19. Deandreaa S, Bravia F, Turatia F, et al. Risk factors for falls in older people in nursing homes and hospitals. A systematic review and meta-analysis. Arch Geriatr Gerontol 2013;56:407-415.

20. Hanlon J, Zhao X, Naples J, et al. Central nervous system medication burden and serious falls in older nursing home residents. J am Geriatr Soc 2017;65:1183-1189.

21. Neils-Strunjas J, Crandall KJ, Ding X, et al. Facilitators and barriers to attendance in a nursing home exercise program. J Am Med Dir Assoc 2020; Oct 29:S15258610(20)30806-9. Doi. 10.106/j.jamda.2020.09.023. Epub ahead of print.

22. Miller DK, Morrison MJ, Blair SD, Miller JP, Morley JE. Predilection for frailty remedial strategies among black and white seniors. South Med J 1998;91:375-380.

23. Morley JE. F3ALLS approach to preventing falls. J Nutr Health Aging 2018;22:748750

24. Center for Disease Control and Prevention. National Center for Health Statistics. 2020. https://www.cdc.gov/nchs/fastats/alzheimers.htm (Accessed Nov 10, 2020).

25. Fick DM, Steis MR, Waller JL, Inouye SK. Delirium superimposed on dementia is associated with prolonged length of stay and poor outcomes in hospitalized older adults. J Hosp Med 2013;8:500-505.

26. Kiely D, Bergmann M, Murphy K, et al. Delirium among newly admitted postacute facility patients: Prevalence, symptoms, and severity. J Gerontol A Biol Sci Med Sci 2003;58:M441-M445
27. Aschbrenner K, Grabowski DC, Cai S, et al. Nursing home admissions and longstay conversions among persons with and without serous mental illness. J aging Soc Policy. 2011;23:286-304

28. Morley JE. An overview of cognitive impairment. Clin Geriatr Med 2018;34:505 513.

29. Morley JE, Cruz-Oliver DM. Cognitive stimulation therapy. J Am Med Dir Assoc 2014;15:689-691.

30. Morley JE, Berg-Weger M, Lundy J. Editorial: Nonpharmacological treatment of cognitive impairment. J Nutr Health Aging 2018;22:632-633.

31. Marcantonio ER. Delirium in hospitalized older adults. New Engl J Med 2017;377:1456-1466.

32. Siddiqi N, House AO, Holmes JD. Occurrence and outcome of delirium in medical in-patients: A systematic literature review. Age Ageing 2007;35:350-364.

33. Centers for Medicare \& Medicaid Services. August 2020. https://www. cms.gov/Medicare/Quality-Initiatives-Patient-Assessment-Instruments/ NursingHomeQualityInits/NHQIMDS30).

34. Fong TG, Tulebaev SR, Inouye SK. Delirium in elderly adults: Diagnosis, prevention and treatment. Nat Rev Neurol 2009;5:210-220.

35. Morley JE, Vellas B. Editorial: COVID-19 and older adults. J Nutr Health Aging 2020;24:364-365.

36. Morley JE. Editorial: COVID-19 - the long road to recovery. J Nutr Health Aging 2020;24:917-919. 